Article

\title{
Supplier Selection and Performance Evaluation for High-Voltage Power Film Capacitors in a Fuzzy Environment
}

\author{
Chun-Ming Yang ${ }^{1}{ }^{\circledR}$, Kuen-Suan Chen ${ }^{2,3, *}$, Ting-Hsin Hsu ${ }^{4, *}$ and Chang-Hsien Hsu ${ }^{5}$ \\ 1 Business School, Guilin University of Technology, No. 12, Jiangan Rd., Guilin 541004, China; \\ vicyang0706@gmail.com \\ 2 Department of Industrial Engineering and Management, National Chin-Yi University of Technology, \\ Taichung 41170, Taiwan \\ 3 Department of Business Administration, Chaoyang University of Technology, Taichung 41349, Taiwan \\ 4 Department of Finance, National Taichung University of Science and Technology, North Dist., \\ Taichung 404, Taiwan \\ 5 Department of Business Administration, Asia University, Wufeng, Taichung 41354, Taiwan; pci@asia.edu.tw \\ * Correspondence: kschen@ncut.edu.tw (K.-S.C.); samhsu329@nutc.edu.tw (T.-H.H.)
}

Received: 16 November 2019; Accepted: 29 November 2019; Published: 3 December 2019

check for updates

\begin{abstract}
Rapid advances in technology have shortened the upgrade and replacement cycles in industries such as electronics, household appliances, and communication technologies. Within these industries, high-voltage power film capacitors have become indispensable electrical components due to their good electrical performance and high reliability. The selection and evaluation of suppliers of these capacitors is therefore increasingly important. Suppliers play a crucial role in the electronics industry; the quality of their products determines the degree to which the quality of the final product can be guaranteed. Supplier quality also affects the ability of all the members in a supply chain to control costs. Evaluation by decision-makers is highly significant in the supplier selection process. However, when the opinions of multiple decision-makers are combined, issues such as cognitive differences, fuzzy linguistics, and uncertainty are common. This study presents a supplier performance index $S_{P L}$ and derives the estimates of the index $S_{P L}$ and its statistical properties. The proposed index is not only helpful for the accurate measurement of supplier performance; it can also reduce cognitive differences among evaluators in the decision-making process (that is, the sample variability associated with the Likert scale). Evaluation scores for each criterion for the linguistic labels are converted to triangular fuzzy numbers in order to reduce ambiguity. Subsequently, integrated crisp values are obtained by defuzzification in a fuzzy inference system. A real-world case study of the supplier selection of high-voltage power film capacitors is provided to illustrate the efficacy of the proposed method.
\end{abstract}

Keywords: high voltage power film capacitor; supplier selection; fuzzy theory; performance evaluation

\section{Introduction}

Rapid advances in technology have resulted in the flourishing of the electronics and information industries; as such, the market demand for capacitors increases daily. Capacitors are a type of passive component similar to batteries. They can store electrical currents temporarily as well as block direct currents, couple alternating currents, store energy, and serve as bypasses. There are numerous types of capacitors, each with a wide range of applications; for example, high-voltage power film capacitors are commonly utilized in aircraft, ocean-going vessels, and high-frequency communication products. 
Low-quality high voltage power film capacitors working under high voltage lead to an increased dissipation factor (DF), which damages the internal medium. Continued use under such circumstances can lead to overly-high operating temperatures in the capacitors which result in deformation and burnout. Mild cases may lead to energy drops or failure, while severe cases may result in an explosion. Suppliers must therefore be selected with care.

In traditional supply chain management, members of the supply chain view each other competitively, and the overall concern is keeping costs down. However, if suppliers are selected based on cost alone, a hostile relationship is created between the supplier and buyer, negatively affecting product quality and service [1]. Therefore, companies must evaluate suppliers from multiple angles to protect each other's interests and create good and lasting partnerships [2-4]. In general, managers often deliver their judgments based on individual subjective preferences or experience, or adopt Likert-type questionnaires to score supplier characteristics. However, many researchers [5-7] have argued that the Likert scale cannot appropriately reflect the feelings of an evaluator toward certain quantitative indices. For instance, an evaluator may think that the level of service provided by a supplier falls somewhere between acceptable and satisfactory. This brings uncertainty to the decision-making process. Information loss may also take place when the opinions of decision-makers are combined. As a consequence, it is difficult for company managers to collect accurate information by which they can select suitable suppliers, hindering their ability to formulate appropriate management strategies.

Fuzzy theory can be used to define data or statuses that cannot be described in detail, such as color preferences or age groups. Their purpose is to assist decision makers or researchers in expressing the information conveyed by their data in a more precise manner [8]. One approach in fuzzy theory, called the membership function, presents the degrees of fuzziness in the research subjects using values between 0 and 1 . This approach enumerates subjective judgments so that the results better match human thinking patterns. Fuzzy theory can be used to define the grade of membership of different actors in different groups, and the factors (criteria) defining this membership are not necessarily only linguistic. Fuzzy theory has an extremely wide range of applications. Fuzzy theory research can be found in fields ranging from engineering and technology to social sciences, such as robot control [9], signal and information processing [10], education [11], and decision-making [12]. In this study, fuzzy theory is commonly applied to describe linguistic ambiguity [12,13]; however, previous studies have neglected to deal with cognitive differences among evaluators in decision-making processes that rely on the Likert scale (that is, variability within the data set). In the past, several multi criteria group decision making (MCGDM) approaches have been employed that address the problem of heterogeneity in evaluations and their consensus [14]; however, these approaches have some disadvantages, such as a lack of data interpretation (that is, how much variation or dispersion is in the data set) and a higher degree of imprecision compared to the traditional statistical methods. In statistics, the standard deviation $\sigma$ is the most widely used concept to measure the dispersion or variation of a dataset relative to its mean. Moreover, from a statistical perspective, an excessively high standard deviation in the analyzed figures can indicate confusion among decision-makers. This scenario can lead to operational problems and performance losses for the company. This study deals with this problem through the development of an approach to supplier selection and performance evaluation that analyzes and quantifies both qualitative and quantitative criteria. The proposed method uses fuzzy theory to convert the fuzzy voice of the decision-maker's demand for service as a crisp value. Then, a supplier performance index $S_{P L}$ is presented for supplier selection and performance assessment. The performance of each supplier is obtained by aggregating crisp values into index $S_{P L}$. A case study of supplier selection for high-voltage power film capacitors demonstrates the efficacy of the proposed index $S_{P L}$.

The rest of this paper is organized as follows. In Section 2, a literature review is presented to summarize related works on fuzzy theory and supplier selection. Section 3 introduces some basic concepts and operations on fuzzy sets and the proposed supplier performance index $S_{P L}$, as well as its properties for supplier evaluation and selection. An illustrative example from a gas turbine factory is 
considered in Section 4 to demonstrate the applicability of the proposed method. Section 5 concludes the article.

\section{Literature Review}

\subsection{Supplier Selection}

Suppliers play crucial roles in supply chain management, producing components, ensuring product quality, and indirectly managing and assisting with the operational costs of their partners [15]. The quality level of their products determines the degree to which the quality of the final product can be guaranteed and the ability of all the members of the supply chain to control costs. For this reason, the selection of the right suppliers is vital for companies. Supplier selection is a decision-making process that involves a number of steps and several criteria-both quantitative and qualitative. Table 1 summarizes important criteria associated with supplier selection. These criteria are as follows:

- Cost/Price: the procurement costs, labor costs, material costs, and transportation costs of a company;

- Quality: the quality of supplier products;

- Delivery period: the time to delivery of the suppliers;

- Technology: the implementation of modern technology;

- Relations: the duration of collaboration and the closeness of relationships with the suppliers;

- Service: the ability of the suppliers to support and coordinate with products or technologies;

- Communication: the ability of the suppliers to respond regarding products or services and communicate with internal and external partners;

- Green: whether the products or packaging of the suppliers have green marks and follow the 3 Rs (reduce, reuse and recycle);

- Sustainability: the impact of the suppliers (or their products) on society, the economy, and the environment.

In addition to conventional quantitative indices such as the quality, delivery period, and cost/price, this also includes qualitative indices such as supplier service, relations, communication, green, and sustainability. The four criteria of cost/price, quality, delivery and service are the most commonly used factors for the supplier evaluation and selection problem.

Researchers have applied a number of evaluation standards to this problem, including the multiple-criteria decision-making (MCDM) model [16], the analytic hierarchy process (AHP) [17], the Technique for Order of Preference by Similarity to Ideal Solution (TOPSIS) [18], and grey analysis [19]. However, most of these methods use crisp numbers to process decision-making information and cannot process uncertain or imprecise information. Furthermore, the imprecision of the information source, including unquantifiable information, incomplete information, and some unknown information, makes it even more difficult to efficiently select suppliers. Thus, these approaches have been ineffective for supplier selection problems due to the high degree of uncertainty in supplier selection. For this, a key issue is how to evaluate and select the most suitable supplier for companies. 
Table 1. Supplier selection criteria.

\begin{tabular}{|c|c|c|c|c|c|c|c|c|c|}
\hline \multirow{2}{*}{ Reference } & \multicolumn{9}{|c|}{ Criterion } \\
\hline & Cost/Price & Quality & Delivery & Technology & Relations & Service & Communication & Green & Sustainability \\
\hline Reference [20] & $\sqrt{ }$ & $\sqrt{ }$ & $\sqrt{ }$ & & $\sqrt{ }$ & & & & \\
\hline Reference [21] & $\sqrt{ }$ & $\sqrt{ }$ & & & & & & & \\
\hline Reference [22] & $\sqrt{ }$ & $\sqrt{ }$ & $\sqrt{ }$ & & & $\sqrt{ }$ & & $\sqrt{ }$ & \\
\hline Reference [23] & $\sqrt{ }$ & $\sqrt{ }$ & $\sqrt{ }$ & & & $\sqrt{ }$ & $\sqrt{ }$ & & \\
\hline Reference [24] & $\sqrt{ }$ & $\sqrt{ }$ & $\sqrt{ }$ & & $\sqrt{ }$ & & & $\sqrt{ }$ & \\
\hline Reference [25] & $\sqrt{ }$ & $\sqrt{ }$ & $\sqrt{ }$ & & & & & & \\
\hline Reference [26] & $\sqrt{ }$ & $\sqrt{ }$ & $\sqrt{ }$ & $\sqrt{ }$ & & $\sqrt{ }$ & & & \\
\hline Reference [27] & $\sqrt{ }$ & $\sqrt{ }$ & $\sqrt{ }$ & & & & & & \\
\hline Reference [28] & $\sqrt{ }$ & & & & & $\sqrt{ }$ & & & \\
\hline Reference [29] & $\sqrt{ }$ & $\sqrt{ }$ & $\sqrt{ }$ & $\sqrt{ }$ & & & & $\sqrt{ }$ & $\sqrt{ }$ \\
\hline Reference [30] & $\sqrt{ }$ & $\sqrt{ }$ & & & & $\sqrt{ }$ & & $\sqrt{ }$ & \\
\hline Reference [31] & $\sqrt{ }$ & $\sqrt{ }$ & $\sqrt{ }$ & & & $\sqrt{ }$ & & $\sqrt{ }$ & \\
\hline Reference [32] & $\sqrt{ }$ & $\sqrt{ }$ & $\sqrt{ }$ & $\sqrt{ }$ & $\sqrt{ }$ & $\sqrt{ }$ & $\sqrt{ }$ & & $\sqrt{ }$ \\
\hline Reference [33] & $\sqrt{ }$ & $\sqrt{ }$ & $\sqrt{ }$ & & & & & & $\sqrt{ }$ \\
\hline Reference [34] & & $\sqrt{ }$ & & $\sqrt{ }$ & & & & & $\sqrt{ }$ \\
\hline
\end{tabular}




\subsection{Fuzzy Theory in Supplier Selection}

Decisions can be described as the final outcome of certain psychological and reasoning processes. They are often based on the judgment of experts and/or the values of stakeholders. Decisions may be influenced by subjectivity and uncertainty, and experts therefore tend to rely on their own standards. However, this expert subjectivity constitutes the main flaw in their decision-making process. Zadeh [35] stated that human thinking and decision-making processes often include impressions, emotions, and intuition. Therefore, as long as there are people involved, uncertainty and ambiguity will be present. This means that traditional two-value logic rarely applies in practice. To solve this problem, Zadeh [8] presented a fuzzy set and the concept of membership grades. Thereafter, various researchers have tackled the supplier evaluation and selection problem in fuzzy environments. Karsak and Dursun [36] presented an integrated fuzzy MCDM method using quality function deployment (QFD) to create a two-tuple linguistic representation model to assess supplier selection in a private hospital in Istanbul. Lima-Junior and Carpinetti [20] utilized a multi-criteria approach based on fuzzy QFD to screen and select the best supplier for a company in the automotive industry. Parkouhi and Ghadikolaei [37] applied the fuzzy analytic network process (ANP) and grey ViseKriterijumska optimizacija i Kompromisno Resenje (VIKOR in Serbian, which means multi-criteria optimization and compromise solution in English) techniques to choose the optimal supplier for firms in the wood and paper industry. Banaeian et al. [38] introduced a fuzzy group decision-making method using TOPSIS, VIKOR, and grey relational analysis (GRA) methods to assess green supplier selection for the agri-food industry. Chen et al. [39] used the six sigma quality indices (SSQIs) to develop a fuzzy green supplier selection model for the performance measurement of thin-film-transistor liquid-crystal display (TFT-LCD) panel manufacturers. Feng et al. [40] developed an integrated fuzzy grey TOPSIS method for supplier assessment and selection for a collaborative manufacturing company. Gupta et al. [41] utilized an integrated fuzzy AHP with multi-attributive border approximation area comparison (MABAC), weighted aggregated sum-product assessment (WASPAS), and TOPSIS to find the most suitable green suppliers for the automotive industry.

In many real-world situations, fuzzy linguistic data are often included in a supplier selection environment since human judgement is usually vague and the decision-making context involves complexity and uncertainty. Under such circumstances, linguistic labels are more appropriate than quantitative values for the description of expert preferences or evaluations. In fuzzy theory, linguistic labels can be expressed as fuzzy numbers using conversion scales. By converting linguistic labels into fuzzy numbers, the fuzzy concepts of "Good" and "Bad" can be converted into clear and computable values. For example, the linguistic labels "Very Good (VG)", "Good (G)", "Normal (N)", "Poor (P)", and "Very Poor (VP)" can be converted to the following triangular fuzzy numbers: "VG $(7,9,10)$ ", “ $\mathrm{G}(5,7,9)$ ", “ $\mathrm{N}(3,5,7)$ ", "P $(1,3,5)$ ", and "VP $(0,1,3)$ ". Table 2 shows these linguistic labels and their corresponding fuzzy numbers [42]. The fuzzy numbers can then be converted into an integrated crisp value through defuzzification.

Table 2. Linguistic labels and their corresponding fuzzy numbers.

\begin{tabular}{cc}
\hline Linguistic Label & Fuzzy Numbers \\
\hline Very Poor (VP)/Very High (VH) & $(0,0,3)$ \\
Poor (P)/High (H) & $(1,3,5)$ \\
Normal (N) & $(3,5,7)$ \\
Good (G)/Low (L) & $(5,7,9)$ \\
Very Good (VG)/Very Low (VL) & $(7,10,10)$ \\
\hline
\end{tabular}

Although these approaches are helpful, supplier selection involves knowledge from multiple fields, and cognitive differences and information loss may take place when the opinions of decision-makers are combined (that is, how much variation or dispersion is in the data set). From a statistical perspective, data with an overly-high standard deviation may indicate the existence of confusion or uncertainty 
by the decision-maker and/or the problem or issue. If companies do not address this, the resulting decision may be poor and affect the operating performance of the company. Thus, companies need an effective approach to address the aforementioned issues.

To demonstrate the superiority of the proposed approach, we compared it to other existing supplier selection methods, the results of which are shown in Table 3. We selected the following existing methods for comparison: TOPSIS [19], ANP [43], Decision Making Trial and Evaluation Laboratory (DEMATEL) [44], and the Preference Ranking Organization Method for Enrichment of Evaluations (PROMETHEE) [45], AHP [46]. The studies conducted by Chen and Zou [19], Bakeshlou et al. [43], and Krishankumar et al. [45] all used numerical simulations to verify the validity of the methods they proposed, and the evaluation criteria adopted by Chen and Zou [19] had no reference basis and were not established by experts. Thus, whether these methods are reasonable is open to question. Furthermore, the investigation conducted by Hu et al. [44] did not take uncertainty or the fuzzy linguistics of evaluators into account. Above all, none of these studies considered cognitive differences among evaluators. Therefore, the proposed method of this study is more reasonable and valid for supplier selection.

Table 3. Comparative analysis.

\begin{tabular}{ccccc}
\hline Reference & $\begin{array}{c}\text { Fuzzy } \\
\text { Linguistics }\end{array}$ & $\begin{array}{c}\text { Cognitive } \\
\text { Differences }\end{array}$ & $\begin{array}{c}\text { Reasonable } \\
\text { Evaluation Criteria }\end{array}$ & $\begin{array}{c}\text { Empirical } \\
\text { Research }\end{array}$ \\
\hline Reference [19] & $\checkmark$ & & & \\
Reference [43] & $\checkmark$ & $\checkmark$ & $\checkmark$ \\
Reference [44] & & & $\checkmark$ & \\
Reference [45] & $\checkmark$ & $\checkmark$ & $\checkmark$ \\
Reference [46] & $\checkmark$ & $\checkmark$ & $\checkmark$ & $\checkmark$ \\
Proposed method & $\checkmark$ & $\checkmark$ & & \\
\hline
\end{tabular}

\section{Material and Methods}

\subsection{Fuzzy Operations for Supplier Evaluation and Selection}

In the universe of discourse $X$, the fuzzy subset $\widetilde{A}$ of $X$ is defined by the membership function $\mu_{\widetilde{A}}(x)$, which maps each element $x$ in $X$ to a real number between 0 and 1 . The function value of $\mu_{\widetilde{A}}(x)$ determines the grade of membership of $X$ in set $\widetilde{A}$. The higher the grade of membership of $x$ in $\widetilde{A}$, the nearer the value of $\mu_{\widetilde{A}}(x)$ is to unity. Kuo et al. [46] pointed out that, in fuzzy theory, the most commonly used fuzzy number is a triangular number fuzzy (TNF) (see Figure 1), the membership function of which is given by the following equation:

$$
\mu_{\widetilde{A}}(x)= \begin{cases}0 & x \leq a \text { or } x \geq c \\ (x-a) /(b-a) & a \leq x \leq b \\ (c-x) /(c-b) & b \leq x \leq c\end{cases}
$$

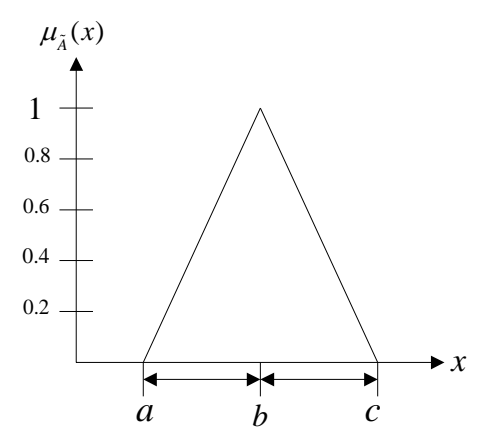

Figure 1. Triangular number fuzzy (TNF). 
Kwong et al. [47] proposed that the needs of customers can be viewed as product perceptions or service perceptions. These form the input data for the following definition of the fuzzy "if-then" rule $R_{j}$ :

$$
R_{j}: \operatorname{If}\left(X_{j 1} \text { is } x_{j 1} \text {, and } X_{j 2} \text { is } x_{j 2}, \ldots \text {, and } X_{j k} \text { is } x_{j k}\right) \text {, then } Y_{j} \text { is } y_{j}
$$

The above rule means that, when the fuzzy set $x_{j 1}, x_{j 2}, \ldots, x_{j k}$ meets the input semantic variables $X_{j 1}, X_{j 2}, \ldots, X_{j k}$, then fuzzy set $y_{j}$ is a semantic variable for output $Y_{j}$. The fuzzy inference process is performed when the input semantic variables $X_{j 1}, X_{j 2}, \ldots, X_{j k}$ become the fuzzy set $x_{j 1}, x_{j 2}, \ldots, x_{j k}$, with membership grades $m_{j 1}, m_{j 2}, \ldots, m_{j k}$.

Hsieh et al. [48] proposed the application of a fuzzy rule to determine fuzzy subsets using intersection. The membership function for this rule is defined as follows:

$$
\mu_{\widetilde{x}}(x)=\min \left\{\mu_{\widetilde{x} j 1}(x), \mu_{\widetilde{x} j 2}(x), \ldots, \mu_{\widetilde{x} j k}(x)\right\}
$$

A fuzzy rule that uses union to determine subsets has the following membership function:

$$
\mu_{\widetilde{x}}(x)=\max \left\{\mu_{\tilde{x} j 1}(x), \mu_{\widetilde{x} j 2}(x), \ldots, \mu_{\widetilde{x} j k}(x)\right\}
$$

Therefore, the membership grades for input $m_{j}$ and output $o_{j}$ of the fuzzy inferences are

$$
\begin{aligned}
m_{j} & =\min \left\{m_{j 1}, m_{j 2}, \ldots, m_{j k}\right\} \\
o_{j} & =\max \left\{o_{j 1}, o_{j 2}, \ldots, o_{j k}\right\}
\end{aligned}
$$

Because " $Y_{j}$ is $y_{j}$ " is the result of its membership grade for $R_{j}$, it can be equated to $o_{j}$, as follows:

$$
Y_{j} \text { is } y_{j 1}: o_{j 1} ; Y_{j} \text { is } y_{j 2}: o_{j 2} ; \ldots ; Y_{j} \text { is } y_{j n}: o_{j n}
$$

After the rules are established, all fuzzy relations and ambiguity semantic assessments are aggregated into a complete fuzzy area. In order to obtain a more comprehensive output, the center of gravity method is adopted to obtain crisp value $\beta_{j}$. The center of gravity method is defined as follows:

$$
\beta_{j}=\int_{a}^{b} x u(x) d x / \int_{a}^{b} u(x) d x
$$

where $a$ and $b$ represent the boundary between the lower and upper bounds of $Y_{j}$ (the output semantic variable).

\subsection{Fuzzy-Rule-Based System for Supplier Evaluation and Selection}

A fuzzy system is a control system based on fuzzy logic. This mathematical system is based on the logical variables of the simulated inputs of logical variable analysis (these logical variables are consecutive values between 0 and 1 rather than the conventional Boolean logic). A fuzzy system is a good way of processing the uncertainty in decision-making. In a fuzzy system, fuzzy inference is the process of using fuzzy logic to map from a given input to an output [48]. The fuzzy inference process involves five phases: (1) fuzzification, (2) application of logical operators in the antecedent of each rule, (3) implication to the consequent of each rule, (4) aggregation of consequents, and (5) defuzzification. An overview of the fuzzy inference process is shown in Figure 2. 


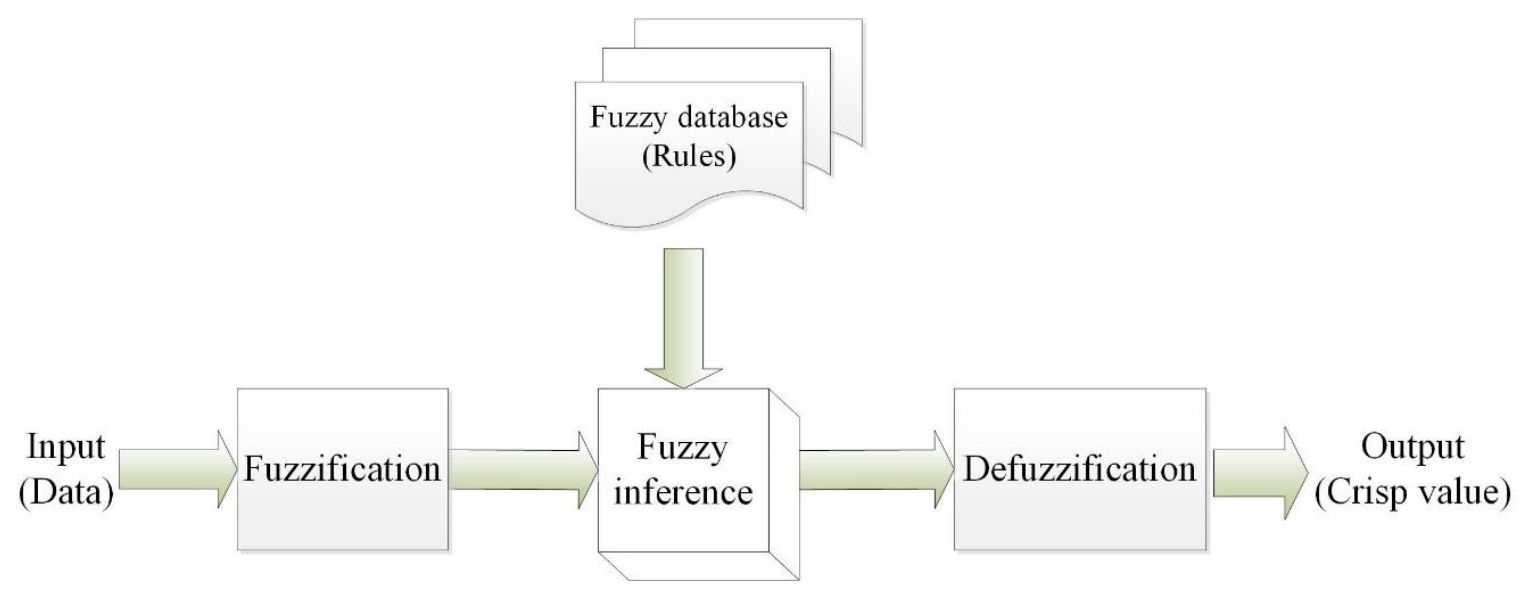

Figure 2. Fuzzy inference process.

For convenience, crisp values are obtained using the Fuzzy Logic Toolbox from MATLAB 2017b (The MathWorks, Inc., Natick, USA). In this study, the input is a linguistic variable and the output is a crisp numerical value (in this case, the intervals for the input and output all are between 0 and 10). Figures $3-5$ show the input linguistic labels, output crisp numerical values, and fuzzy rules as applied in the Fuzzy Logic Toolbox. Figure 3 shows the membership functions of the five fuzzy sets for the input "linguistic labels". Figure 4 shows the seven membership functions of the output "crisp numerical values". In total, 72 fuzzy rules were developed for the proposed method as shown in Figure 5.

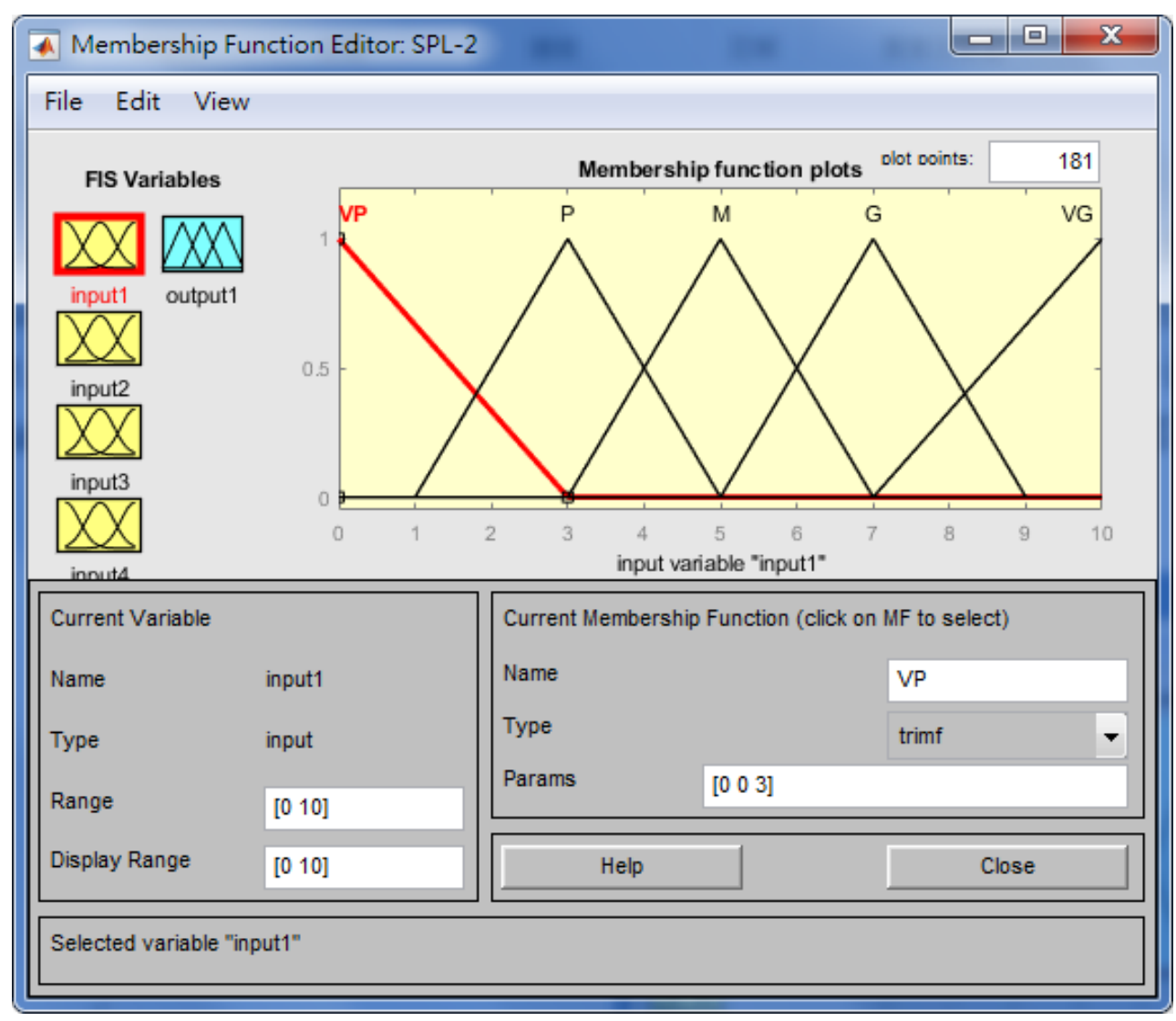

Figure 3. Input linguistic labels. 


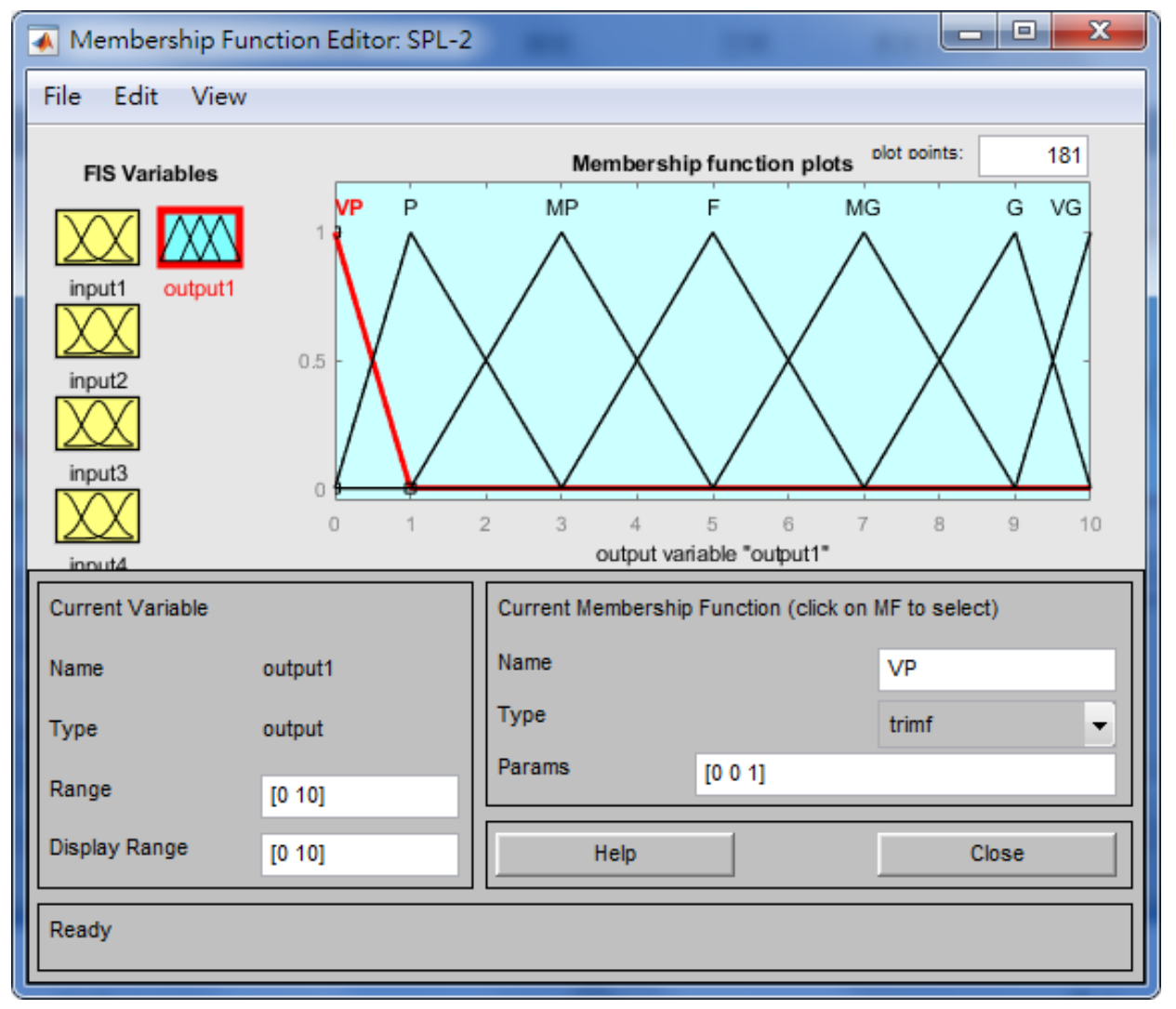

Figure 4. Output crisp numerical values.

An example of supplier selection is used to illustrate the fuzzy inference process. First of all, using a five-point Likert scale questionnaire, a score between 1 (Very Poor (VP)/Very High (VH)) and 9 (Very Good (VG)/Very Low (VL)) can be obtained for four evaluation criteria (cost/price, quality, delivery and service). The score for each evaluation criterion was obtained by a decision maker as follows: price $($ Low $=7)$, quality (Very Good $=9$ ), delivery $($ Normal $=5)$, and service (Very Good $=9$ ). During the fuzzification process, the inputs Low $=7$, Very Good $=9$, Normal $=5$, and Very Good $=9$ are fuzzified according to the corresponding membership functions. After the fuzzy rule reasoning, the output crisp numerical value among the four inputs can be computed using the Fuzzy Logic Toolbox from MATLAB 2017b as 86.4. Figure 5 shows the process of max-min fuzzy inferencing for computing the fuzzy output crisp numerical value. From Figure 5, it can be seen that only fuzzy rule 68 was executed, and the last row of the output column shows the results of max-min inferencing for the only fuzzy rule. In this case, the center of gravity method was used in the defuzzification process. 


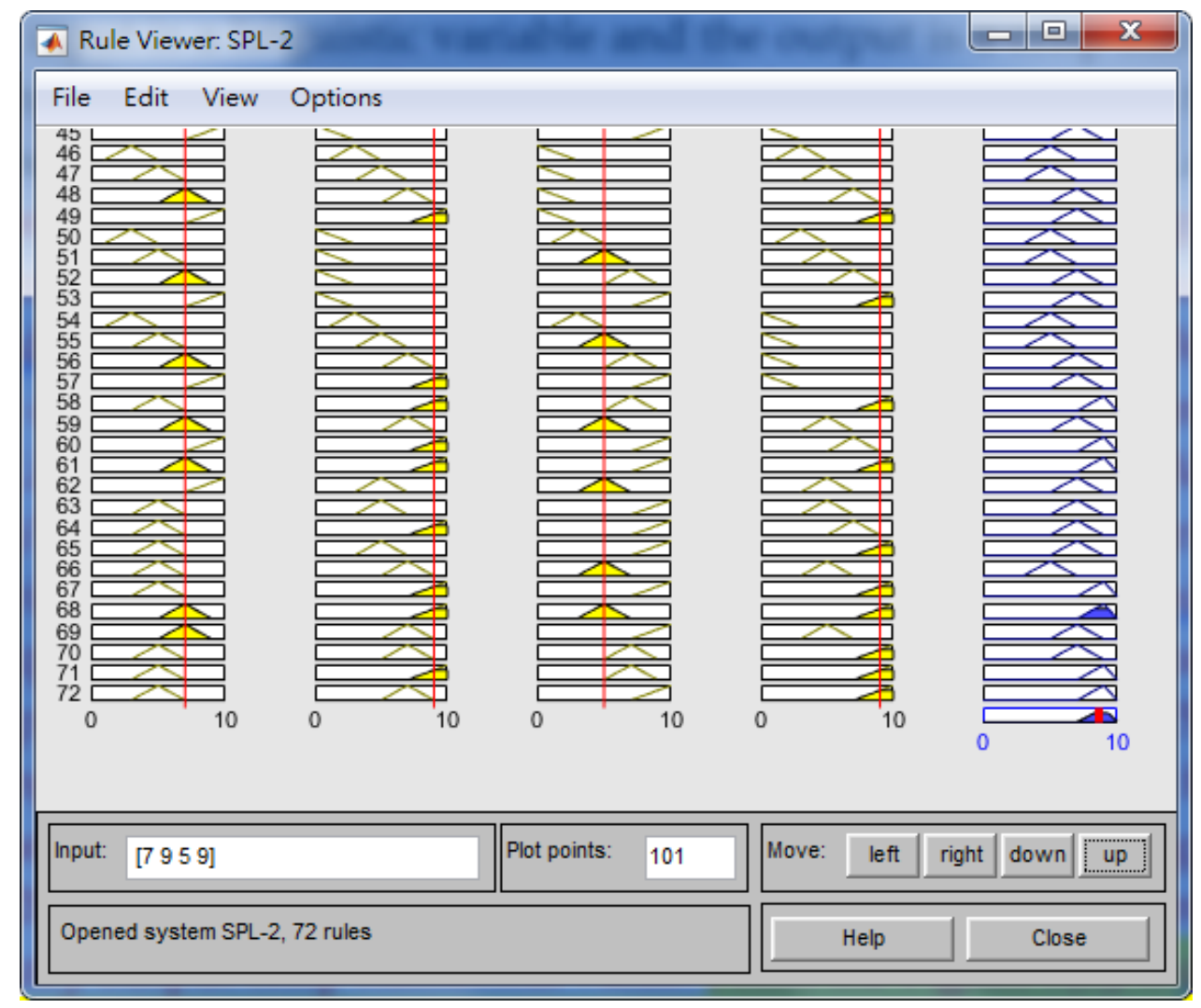

Figure 5. Fuzzy rule.

\subsection{Supplier Performance Index}

Kaya and Kahraman [49] and Yang et al. [50] indicated that the application of statistical techniques and methods can help managers in risk assessment and other decision-making processes. The proposed supplier performance index $S_{P L}$ not only measures supplier performance, but also reduces cognitive differences among multiple decision-makers.

In general, companies want suppliers to provide high-quality products or services [51-55]; that is, the higher the better. Therefore, under the assumption of normality, a supplier performance index $S_{P L}$ can be derived based on the following concept proposed by Kane [56]:

$$
S_{P L}=\frac{\mu-L P B}{3 \sigma}
$$

where $L P B$ denotes the lower performance bound of the supplier, $\mu$ is the mean, and $\sigma$ is standard deviation.

In practice, the parameters $\mu$ and $\sigma$ are typically unknown and must be estimated using the sample data. Hence, the estimated index of $S_{P L}$ can be given as

$$
\widetilde{S}_{P L}=\frac{\bar{X}-L P B}{3 s}
$$

where $\bar{X}$ estimates $\mu$ and the sample standard deviation $s$ estimates $\sigma$.

Since the natural estimator $\widetilde{S}_{P L}$ is a biased estimator of $S_{P L}$ and inappropriate for precisely evaluating the supplier performance, a correction factor $b_{n}$ can be added to obtain the unbiased estimator of $\widetilde{S}_{P L}$ for $S_{P L}$ as follows [57]:

$$
\hat{S}_{P L}=\left(b_{n}\right) \times \widetilde{S}_{P L}
$$


where $b_{n}$ is a function of $n$ and is determined by

$$
b_{n}=\frac{\sqrt{2} \times \Gamma[(n-1) / 2]}{\sqrt{n-1} \times \Gamma[(n-2) / 2]}, n>2
$$

In fact, the unbiased estimator $\hat{S}_{P L}$ is only the function of $\left(\bar{X}, s^{2}\right)$. Because the distribution of $\left(\frac{3 \sqrt{n}}{b_{n}}\right) \times \hat{S}_{P L}$ is a non-central $t$ distribution with $n-1$ degrees of freedom, the non-central parameter $\gamma$ of this distribution is $3 \sqrt{n} \times S_{P L}$, often denoted as $t_{n-1}^{\prime}(\gamma)$. Hence, $\hat{S}_{P L}$ can be rewritten as follows:

$$
\hat{S}_{P L}=\left(\frac{b_{n}}{3}\right) \times \sqrt{\frac{n-1}{n}} \times(K)^{-1 / 2} \times(Z)
$$

where $Z=\sqrt{n} \times \frac{(\bar{X}-L P B)}{\sigma}$ obeys $N\left(3 \sqrt{n} \times S_{P L}, 1\right)$ and $K=\frac{(n-1) s^{2}}{\sigma^{2}}$ obeys $\chi_{n-1}^{2}$.

Under the assumption of normal distribution, $\bar{X}$ and $s^{2}$ are independent of each other, so

$$
\begin{aligned}
& E\left(\hat{S}_{P L}\right)^{2}=\left(\frac{b_{n}}{3}\right)^{2} \times\left(\frac{n-1}{n}\right) \times E(K)^{-1} \times E(Z)^{2}=\left(\frac{b_{n}}{3}\right)^{2} \times\left(\frac{n-1}{n}\right) \times\left(\frac{\Gamma[(n-3) / 2]}{2 \Gamma[(n-1) / 2]}\right) \times\left[9 n\left(S_{P L}\right)^{2}+1\right] \\
& \operatorname{Var}\left(\hat{S}_{P L}\right)=E\left(\hat{S}_{P L}\right)^{2}-E^{2}\left(\hat{S}_{P L}\right)=\left(\frac{\Gamma[(n-1) / 2] \Gamma[(n-3) / 2]}{\Gamma^{2}[(n-2) / 2]}\right)\left[(1 / 9 n)+\left(S_{P L}\right)^{2}\right]-\left(S_{P L}\right)^{2}
\end{aligned}
$$

For the further derivation of the probability density function (PDF) of $\hat{S}_{P L}$, we let $W=\frac{3 \sqrt{n}}{b_{n}} \times \hat{S}_{P L}=$ $\frac{Z}{\sqrt{K /(n-1)}}$ obey the distribution of $w_{n-1}^{\prime}(\gamma)$ and $Q=\hat{S}_{P L}=\frac{b_{n}}{3 \sqrt{n}} \times W$. Then, there exists a one-to-one mathematical relationship between $W$ and $Q$. Hence,

$$
f_{Q}(q)=f_{W}(w)\left|\frac{d_{Q}}{d_{W}}\right| \text {, where }\left|\frac{d_{Q}}{d_{W}}\right|=\frac{3 \sqrt{n}}{b_{n}}
$$

and

$$
f_{W}(w)=\frac{2^{-(n / 2)}}{\Gamma[(n-1) / 2]} \int_{0}^{\infty} x^{\left(\frac{n-2}{2}\right)} \times \exp \left\{-\frac{1}{2}\left[x+\left(w \sqrt{\frac{x}{(n-1)}}-\delta\right)^{2}\right]\right\} d x, w \in R
$$

where $R$ is a real number. Then,

$$
f_{\hat{S}_{P L}}(q)=f_{W}\left(\frac{3 \sqrt{n}}{b_{n}} q\right)\left(\frac{3 \sqrt{n}}{b_{n}}\right)=\left(\frac{2^{-(n / 2)} b_{n}^{-1} \sqrt{n}}{3 \Gamma[(n-1) / 2]}\right) \int_{0}^{\infty} w^{\left(\frac{n-2}{2}\right)} \exp \left\{-\frac{1}{2}\left[w+\left(\frac{\sqrt{n w}}{(n-1) b_{n}}\left(\frac{1}{3}\right) q-\gamma\right)^{2}\right]\right\} d t, q \in R
$$

Under the assumption of normal distribution, $\hat{S}_{P L}$ is the uniform minimum-variance unbiased estimator (UMVUE) of $S_{P L}$; hence, the PDF of the best estimator $S_{P L}$ is derived as follows:

$$
f_{\hat{S}_{P L}}(q)=\left(\frac{2^{-(n / 2)} b_{n}^{-1} \sqrt{n}}{3 \Gamma[(n-1) / 2]}\right) \int_{0}^{\infty} w^{\left(\frac{n-2}{2}\right)} \times \exp \left\{-\frac{1}{2}\left[w+\left(\frac{\sqrt{n w}}{(n-1) b_{n}} \times\left(\frac{1}{3}\right) q-\gamma\right)^{2}\right]\right\} d w, q \in R
$$

For convenience in the calculation of $\hat{S}_{p o}$, Table 4 lists the values of $b_{n}$ with varying $n$. 
Table 4. Values of $b_{n}$ with varying $n$.

\begin{tabular}{cccccccc}
\hline $\boldsymbol{n}$ & $\boldsymbol{b}_{\boldsymbol{n}}$ & $\boldsymbol{n}$ & $\boldsymbol{b}_{\boldsymbol{n}}$ & $\boldsymbol{n}$ & $\boldsymbol{b}_{\boldsymbol{n}}$ & $\boldsymbol{n}$ & $\boldsymbol{b}_{\boldsymbol{n}}$ \\
\hline 3 & 0.580 & 10 & 0.914 & 17 & 0.952 & 24 & 0.967 \\
4 & 0.725 & 11 & 0.923 & 18 & 0.955 & 25 & 0.968 \\
5 & 0.798 & 12 & 0.930 & 19 & 0.958 & 26 & 0.970 \\
6 & 0.841 & 13 & 0.936 & 20 & 0.960 & 27 & 0.971 \\
7 & 0.869 & 14 & 0.941 & 21 & 0.962 & 28 & 0.972 \\
8 & 0.888 & 15 & 0.945 & 22 & 0.964 & 29 & 0.973 \\
9 & 0.903 & 16 & 0.949 & 23 & 0.965 & 30 & 0.974 \\
\hline
\end{tabular}

Chen et al. [58] created a quick-reference guide for the supplier selection problem, which consider the supplier's evaluation scores and corresponding performance levels (see Table 5). As noted in Table 5, if the supplier's evaluation score is higher than 75, the supplier's performance level is labeled "excellent": buyers will order again and suppliers will not change their model. If the supplier's evaluation score is greater than or equal to 60 or less than or equal to 75 , the supplier's performance is considered "good" and buyers will order again, but suppliers should prevent their product quality from falling. If the supplier's evaluation score is greater than 30 or less than 60 , the supplier's performance level is "fair" and buyers will decline to order again unless the buyer is willing to reduce the level of demand. If the supplier's evaluation score is less than or equal to 30, the supplier's performance is considered "poor": buyers will decline to order and suppliers should improve product quality. According to Chen et al. [58], when the supplier's evaluation score is less than 60, the buyer will decline to order again unless the buyer is willing to reduce his or her level of demand for products or services. Therefore, we set 60 as the $L P B$ to measure supplier performance.

Table 5. Supplier performance guide.

\begin{tabular}{|c|c|c|}
\hline Score & Performance & Result \\
\hline Crisp value $>75$ & Excellent & Buyers will order again, and suppliers will not change their model. \\
\hline $60 \leq$ Crisp value $\leq 75$ & Good & $\begin{array}{l}\text { Buyers will order again, but suppliers should prevent their } \\
\text { product quality from falling. }\end{array}$ \\
\hline $30<$ Crisp value $<60$ & Fair & $\begin{array}{l}\text { Buyers will decline to order again unless the buyer is willing to } \\
\text { reduce the level of demand. }\end{array}$ \\
\hline Crisp value $\leq 30$ & Poor & $\begin{array}{c}\text { Buyers will decline to order, and suppliers should improve } \\
\text { product quality. }\end{array}$ \\
\hline
\end{tabular}

\section{Case Study}

In order to illustrate how the proposed method can be utilized in practical applications, we considered a manufacturer of gas turbine engines in Taiwan-Company A. It is one of the few professional gas turbine engine manufacturers in the country. The gas turbine engines are used for power transmission in airplanes, large ships, and automotive vehicles. In the manufacturing of gas turbine engines, high-voltage power film capacitors (see Figure 6) play a crucial role. Capacitors of poor quality can cause continued heat accumulation, rising temperatures, and low heat dissipation efficiency, which may lead to malfunctions and a shortened service life for gas turbine engines. These potential malfunctions can be dangerous, threatening life and property. Moreover, with the technological advances and innovations in materials made in recent years, Company A has developed a series of next-generation gas turbine engines that can achieve the same performance as previous gas turbine engines using only half of the specifications and materials. To increase the market share of their existing products in the current market and enable their new products to penetrate the market, Company A must employ an effective approach to evaluate the product performance of high-voltage power film capacitor suppliers in manufacturing high-quality gas turbine engines. The proposed method was used to achieve these ends. 


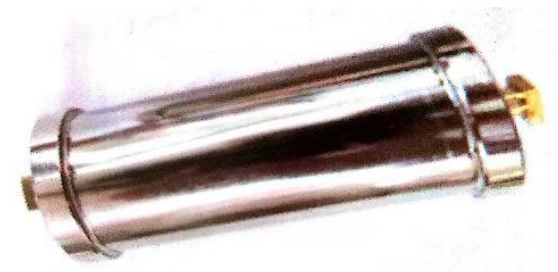

Figure 6. High-voltage power film capacitor.

Following consultation with experts and Company A's managers, and with reference to Table 1 , Company A decided to adopt the following four criteria to evaluate the capability levels of three suppliers of high voltage power film capacitors: delivery (C1), price (C2), quality (C3), and service (C4). Among these four criteria, $\mathrm{C} 1$ and $\mathrm{C} 2$ are cost criteria and the remaining are benefit criteria. The five-point Likert scale questionnaire was adopted for the assessment of these suppliers by six managers (decision-makers). The six managers that were chosen all had more than 10 years' experience in executive positions. Table 6 presents the positions and experience of these six managers.

Table 6. Positions and experience of decision-makers.

\begin{tabular}{ccc}
\hline Manager & Position & Experience (Year) \\
\hline Manager 1 & General manager & 15 \\
Manager 2 & Quality manager & 12 \\
Manager 3 & Merchandising manager & 10 \\
Manager 4 & Production manager & 17 \\
Manager 5 & Sales manager & 12 \\
Manager 6 & Operations manager & 13 \\
\hline
\end{tabular}

Since the linguistic information provided by the managers represents qualitative data, fuzzy theory is used to convert each linguistic variable into a fuzzy number (quantification). For example, the linguistic labels \{Very High; High; Normal; Low; Very Low\} for the cost criteria (delivery and price) were converted to the following fuzzy numbers: $\{(0,0,3),(1,3,5),(3,5,7),(5,7,9)$, and $(7,10,10)\}$, and the linguistic labels \{Very Poor; Poor; Normal; Good; Very Good\} for the benefit criteria (quality and service) were converted to the following fuzzy numbers: $\{(0,0,3),(1,3,5),(3,5,7),(5,7,9)$, and $(7$, $10,10)\}$. Subsequently, crisp values were obtained using the Fuzzy Logic Toolbox from MATLAB 2017b. The results are shown in Tables 7-9.

Table 7. Results of Supplier 1.

\begin{tabular}{|c|c|c|c|c|c|}
\hline Criterion & C1 (Cost) & C2 (Cost) & C3 (Benefit) & C4 (Benefit) & Crisp Value \\
\hline Manager 1 & N (5) & $\mathrm{G}(7)$ & VG (9) & VG (9) & 86.4 \\
\hline Manager 2 & $\mathrm{~L}(7)$ & L (7) & VG (9) & $\mathrm{N}(5)$ & 70 \\
\hline Manager 3 & $\mathrm{~L}(7)$ & $\mathrm{L}(7)$ & $G(7)$ & $G(7)$ & 86.7 \\
\hline Manager 4 & VL (9) & $\mathrm{N}(5)$ & VG (9) & N (5) & 70 \\
\hline Manager 5 & $\mathrm{~N}(5)$ & L (7) & $\mathrm{G}(7)$ & VG (9) & 70 \\
\hline Manager 6 & VL (9) & $\begin{array}{l}\mathrm{VL}(9) \\
\bar{X}=\mathbf{8 0 . 0} \\
s=\mathbf{1 1 . 5}\end{array}$ & VG (9) & VG (9) & 96.7 \\
\hline
\end{tabular}


Table 8. Results of Supplier 2.

\begin{tabular}{|c|c|c|c|c|c|}
\hline Criterion & C1 (Cost) & C2 (Cost) & C3 (Benefit) & C4 (Benefit) & Crisp Value \\
\hline Manager 1 & N (5) & VL (9) & $\mathrm{G}(7)$ & VG (9) & 86.4 \\
\hline Manager 2 & $\mathrm{~L}(7)$ & VL (9) & $\mathrm{N}(5)$ & $\mathrm{G}(7)$ & 70 \\
\hline Manager 3 & VL (9) & $\mathrm{N}(5)$ & $\mathrm{G}(7)$ & $\mathrm{N}(5)$ & 70 \\
\hline Manager 4 & $\mathrm{~L}(7)$ & $\mathrm{N}(5)$ & VG (9) & G (7) & 70 \\
\hline Manager 5 & $\mathrm{~L}(7)$ & $\mathrm{L}(7)$ & $\mathrm{G}(7)$ & $\mathrm{G}(7)$ & 86.7 \\
\hline \multirow[t]{2}{*}{ Manager 6} & VL (9) & $\mathrm{N}(5)$ & $\mathrm{N}(5)$ & VG (9) & 70 \\
\hline & & $\begin{aligned} \bar{X} & =75.5 \\
s & =8.5\end{aligned}$ & & & \\
\hline
\end{tabular}

Table 9. Results of Supplier 3.

\begin{tabular}{|c|c|c|c|c|c|}
\hline Criterion & C1 (Cost) & C2 (Cost) & C3 (Benefit) & C4 (Benefit) & Crisp Value \\
\hline Manager 1 & VL (9) & VL (9) & G (9) & VG (9) & 96.7 \\
\hline Manager 2 & $\mathrm{~N}(5)$ & $\mathrm{L}(7)$ & $\mathrm{N}(5)$ & $\mathrm{N}(5)$ & 50 \\
\hline Manager 3 & $\mathrm{~L}(7)$ & $\mathrm{L}(7)$ & $\mathrm{N}(5)$ & VG (9) & 70 \\
\hline Manager 4 & VL (9) & VL (9) & G (9) & VG (9) & 96.7 \\
\hline Manager 5 & $\mathrm{~L}(7)$ & $\mathrm{N}(5)$ & $\mathrm{N}(5)$ & VG (9) & 70 \\
\hline Manager 6 & VL (9) & $\begin{array}{l}\mathrm{VL}(9) \\
\bar{X}=\mathbf{7 5 . 5} \\
S=\mathbf{1 8 . 1 1}\end{array}$ & N (5) & $N(5)$ & 70 \\
\hline
\end{tabular}

The mean $\bar{X}$ is found for each supplier, resulting in the following ranking: Supplier $1(\bar{X}=80)>$ Supplier $2=$ Supplier $3(\bar{X}=75.5)$. A more accurate measurement of the performances of the three suppliers can be obtained using Equation (9), as follows:

$$
\begin{gathered}
\widetilde{S}_{P L 1}=\frac{(80-60)}{3 \times 11.5}=0.577, \\
\widetilde{S}_{P L 2}=\frac{(75.5-60)}{3 \times 8.5}=0.605, \\
\widetilde{S}_{P L 3}=\frac{(75.5-60)}{3 \times 18.11}=0.285 .
\end{gathered}
$$

According to Table 2, when $n=6, b_{n}$ is 0.841 . Hence, using Equation (12), we obtain the following:

$$
\begin{aligned}
& \hat{S}_{P L 1}=0.577 \times 0.841=0.485, \\
& \hat{S}_{P L 2}=0.605 \times 0.841=0.509, \\
& \hat{S}_{P L 3}=0.285 \times 0.841=0.240 .
\end{aligned}
$$

As a result, we can re-rank the performance of the suppliers as follows: Supplier $2\left(\hat{S}_{P L 2}=0.509\right)$ $>$ Supplier $1\left(\hat{S}_{P L 1}=0.485\right)>$ Supplier $3\left(\hat{S}_{P L 3}=0.240\right)$. Therefore, Supplier 2 is the best choice for Company A.

\section{Conclusions}

In the supply chain, each company is dependent upon others in the line; therefore, supply chain members can work together to reduce operational costs and improve productivity and performance. However, a key question is how to measure and select the most suitable supplier. Generally speaking, managers often rely on past personal experience or subjective assertions, or adopt the Likert scale to evaluate, compare, and rank the performance of suppliers. However, these approaches have some 
disadvantages. They tend to neglect stakeholders' preferences as well as cognitive differences among evaluators. Furthermore, when the opinions of multiple decision-makers are combined, issues such as cognitive differences, fuzzy linguistics, and uncertainty are common. To fill these gaps, this study presents a supplier performance index $S_{P L}$, and derives the estimator $\hat{S}_{P L}$ and its PDF. Subsequently, the Fuzzy Logic Toolbox from MATLAB 2017b is used to obtain crisp values in a fuzzy environment. To demonstrate the efficacy of the proposed method, this study uses a real-world case study for supplier selection of high-voltage power film capacitors for a gas turbine factory. Finally, we compared the proposed method with existing methods.

This paper has two important managerial implications. First, the proposed approach provides guidelines for managers, assisting not only with the problem of cognitive preferences and differences, but also in the solution of the supplier selection problem in the mechanical engineering industry. Second, companies can relay the results of the proposed method to unsuccessful suppliers to give them an understanding of their shortcomings and help them improve their performance, which will enhance the competitiveness of the supply chain and create win-win situations for both parties.

The major contributions of this study are six-fold: (i) when the opinions of multiple decision-makers are combined, the proposed method can effectively resolve issues such as cognitive differences, fuzzy linguistics, and uncertainty in the supplier selection process; (ii) the proposed method enables analysis data to be easily obtained from investigations of buyers and suppliers; (iii) the proposed method can serve as an effective tool with which companies can manage and control the quality of the supplier selection process; (iv) the proposed method can be used by supply chain members to evaluate and determine suitable suppliers in a fuzzy environment; (v) the proposed method could be profitably extended to the process of supplier selection in other industries; and (vi) evaluation data that follow a non-normal skewed distribution could also be considered for supplier selection [59].

Author Contributions: Conceptualization, C.-M.Y. and C.-H.H.; Data curation, T.-H.H. and C.-H.H.; Formal analysis, C.-M.Y. and K.-S.C.; Funding acquisition, C.-M.Y. and K.-S.C.; Methodology, C.-M.Y. and C.-H.H.; Project administration, T.-H.H.; Software, C.-M.Y.; Supervision, K.-S.C. and C.-H.H.; Validation, K.-S.C., T.-H.H. and C.-H.H.; Visualization, T.-H.H.; Writing—original draft, C.-M.Y.; Writing—review \& editing, C.-M.Y., K.-S.C., T.-H.H. and C.-H.H.

Funding: This research was funded by National Natural Science Foundation of China, grant number 71762008, Guilin University of Technology, grant number GUTQDJJ6616075 and the Ministry of Science and Technology Taiwan, grant number MOST 107-2622-E-167-003-CC3.

Conflicts of Interest: The authors declare no conflict of interest.

\section{References}

1. Dyer, J.H. Effective interfirm collaboration: How firms minimize transaction costs and maximize transaction value. Strategic Manage. J. 1997, 18, 535-556. [CrossRef]

2. Chen, K.L.; Chen, K.S.; Li, R.K. Suppliers capability and price analysis chart. Int. J. Prod. Econ. 2005, 98, 315-327. [CrossRef]

3. Fallahpour, A.; Olugu, E.U.; Musa, S.N.; Wong, K.Y.; Noori, S. A decision support model for sustainable supplier selection in sustainable supply chain management. Comput. Ind. Eng. 2017, 105, 391-410. [CrossRef]

4. Govindan, K.; Shankar, M.; Kanna, D. Supplier selection based on corporate social responsibility practices. Int. J. Prod. Econ. 2018, 200, 353-379. [CrossRef]

5. Benítez, J.M.; Martín, J.C.; Román, C. Using fuzzy number for measuring quality of service in the hotel industry. Tour. Manage. 2007, 28, 544-555. [CrossRef]

6. Juan, Y.K.; Perng, Y.H.; Castro-Lacouture, D.; Lu, K.S. Housing refurbishment contractors selection based on a hybrid fuzzy-QFD approach. Automat. Constr. 2009, 18, 139-144. [CrossRef]

7. Chou, C.C.; Liu, L.J.; Huang, S.F.; Yih, J.M.; Han, T.C. An evaluation of airline service quality using the fuzzy weighted SERVQUAL method. Appl. Soft Comput. 2011, 11, 2117-2128. [CrossRef]

8. Zadeh, L.A. The concept of a linguistic variable and its application to approximate reasoning. Inf. Sci. 1975, 8, 199-249. [CrossRef] 
9. Mohanta, J.C.; Keshari, A. A knowledge based fuzzy-probabilistic roadmap method for mobile robot navigation. Appl. Soft Comput. 2019, 79, 391-409. [CrossRef]

10. Lin, P.H.; Jin, Y.M. Applying fuzzy theory in selecting the image quality factors of 3D televisions. Int. J. Ind. Ergonom. 2019, 74, 102841. [CrossRef]

11. Plewa, C.; Ho, J.; Conduit, J.; Karpen, I.O. Reputation in higher education: A fuzzy set analysis of resource configurations. J. Bus. Res. 2016, 69, 3087-3095. [CrossRef]

12. Akman, G. Evaluating suppliers to include green supplier development programs via fuzzy c-means and VIKOR methods. Comput. Ind. Eng. 2015, 86, 69-82. [CrossRef]

13. Cid-López, A.; Hornos, M.J.; Carrasco, R.A.; Herrera-Viedma, E. Applying a linguistic multi-criteria decision-making model to the analysis of ICT suppliers' offers. Expert Syst. Appl. 2016, 57, 127-138. [CrossRef]

14. Garcia, N.; Puente, J.; Fernandez, I.; Priore, P. Suitability of a consensual fuzzy inference system to evaluate suppliers of strategic products. Symmetry 2018, 10, 22. [CrossRef]

15. Wu, Y.; Chen, K.; Zeng, B.; Xu, H.; Yang, Y. Supplier selection in nuclear power industry with extended VIKOR method under linguistic information. Appl. Soft Comput. 2016, 48, 444-457. [CrossRef]

16. Wang, Y.J.; Lee, H.S. Generalizing TOPSIS for fuzzy multiple-criteria group decision-making. Comput. Math Appl. 2007, 53, 1762-1772. [CrossRef]

17. Kuo, R.J.; Lee, L.Y.; Hu, T.L. Developing a supplier selection system through integrating fuzzy AHP and fuzzy DEA: a case study on an auto lighting system company in Taiwan. Prod. Plan. Control Manage. Oper. 2010, 21, 468-484. [CrossRef]

18. Junior, F.R.L.; Osiro, L.; Carpinetti, L.C.R. A comparison between Fuzzy AHP and Fuzzy TOPSIS methods to supplier selection. Appl. Soft Comput. 2014, 21, 194-209. [CrossRef]

19. Chen, W.; Zou, Y. An integrated method for supplier selection from the perspective of risk aversion. Appl. Soft Comput. 2017, 54, 449-455. [CrossRef]

20. Junior, F.R.L.; Carpinetti, L.C.R. A multicriteria approach based on fuzzy QFD for choosing criteria for supplier selection. Comput. Ind. Eng. 2016, 101, 269-285. [CrossRef]

21. Jeang, A.; Chung, C.P. Process capability analysis based on minimum production cost and quality loss. Int. J. Adv. Manuf. Tech. 2009, 43, 710-719. [CrossRef]

22. Kuo, R.J.; Wang, Y.C.; Tien, F.C. Integration of artificial neural network and MADA methods for green supplier selection. J. Clean. Prod. 2010, 18, 1161-1170. [CrossRef]

23. Schramm, F.; Morais, D.C. Decision support model for selecting and evaluating suppliers in the construction industry. Pesqui. Oper. 2012, 32, 643-662.

24. Tseng, M.L.; Chiu, A.S. Evaluating firm's green supply chain management in linguistic preferences. J. Clean. Prod. 2013, 40, 22-31. [CrossRef]

25. Nair, A.; Jayaram, J.; Das, A. Strategic purchasing participation, supplier selection, supplier evaluation and purchasing performance. Int. J. Prod. Res. 2015, 53, 6263-6278. [CrossRef]

26. Plebankiewicz, E.; Kubek, D. Multicriteria selection of the building material supplier using AHP and Fuzzy AHP. J. Constr. Eng. Manage. 2016, 142, 04015057. [CrossRef]

27. Pramanik, D.; Haldar, A.; Mondal, S.C.; Naskar, S.K.; Ray, A. Resilient supplier selection using AHP-TOPSIS-QFD under a fuzzy environment. Int. J. Manage. Sci. Eng. Manage. 2016, 12, 45-54. [CrossRef]

28. Asadabadi, M.R. A customer based supplier selection process that combines quality function deployment, the analytic network process and a Markov chain. Eur. J. Oper. Res. 2017, 263, 1049-1062. [CrossRef]

29. Luthra, S.; Govindan, K.; Kannan, D.; Mangla, S.K.; Garg, C.P. An integrated framework for sustainable supplier selection and evaluation in supply chains. J. Clean. Prod. 2017, 140, 1686-1698. [CrossRef]

30. Babbar, C.; Amin, S.H. A multi-objective mathematical model integrating environmental concerns for supplier selection and order allocation based on fuzzy QFD in beverages industry. Expert Syst. Appl. 2016, 92, 27-38. [CrossRef]

31. Kannan, D.; Govindan, K.; Rajendran, S. Fuzzy Axiomatic Design approach based green supplier selection: A case study from Singapore. J. Clean. Prod. 2015, 96, 194-208. [CrossRef]

32. Osiro, L.; Lima-Junior, F.R.; Carpinetti, L.C.R. A group decision model based on quality function deployment and hesitant fuzzy for selecting supply chain sustainability metrics. J. Clean. Prod. 2018, 183, 964-978. [CrossRef] 
33. Hsu, C.H.; Chang, A.Y.; Luo, W. Identifying key performance factors for sustainability development of SMEs-Integrating QFD and fuzzy MADM methods. J. Clean. Prod. 2017, 161, 629-645. [CrossRef]

34. Li, J.; Fang, H.; Song, W. Sustainability evaluation via variable precision rough set approach: A photovoltaic module supplier case study. J. Clean. Prod. 2018, 192, 751-765. [CrossRef]

35. Zadeh, L.A. Fuzzy sets. Inf. Control 1965, 8, 338-353. [CrossRef]

36. Karsak, E.E.; Dursun, M. An integrated fuzzy MCDM approach for supplier evaluation and selection. Comput. Ind. Eng. 2015, 82, 82-93. [CrossRef]

37. Parkouhi, S.V.; Ghadikolaei, A.S. A resilience approach for supplier selection: Using Fuzzy Analytic Network Process and grey VIKOR techniques. J. Clean. Prod. 2017, 161, 431-451. [CrossRef]

38. Banaeian, N.; Mobli, H.; Fahimnia, B.; Nielsen, I.E.; Omid, M. Green supplier selection using fuzzy group decision making methods: A case study from the agri-food industry. Comput. Oper. Res. 2018, 89, 337-347. [CrossRef]

39. Chen, K.S.; Wang, C.H.; Tan, K.H. Developing a fuzzy green supplier selection model using six sigma quality indices. Int. J. Prod. Econ. 2019, 212, 1-7. [CrossRef]

40. Feng, Y.; Zhang, Z.; Tian, G.; Fathollahi-Fard, A.M.; Hao, N.; Li, Z.; Wang, W.; Tan, J. A novel hybrid fuzzy grey TOPSIS method: Supplier evaluation of a collaborative manufacturing enterprise. Appl. Sci. 2019, 9, 3770. [CrossRef]

41. Gupta, S.; Soni, U.; Kumar, G. Green supplier selection using multi-criterion decision making under fuzzy environment: A case study in automotive industry. Comput. Ind. Eng. 2019, 136, 663-680. [CrossRef]

42. Chen, C.T. Extensions of the TOPSIS for group decision-making under fuzzy environment. Fuzzy Set Syst. 2000, 114, 1-9. [CrossRef]

43. Bakeshlou, E.A.; Khamseh, A.A.; Asl, M.A.G.; Sadeghi, J.; Abbaszadeh, M. Evaluating a green supplier selection problem using a hybrid MODM algorithm. J. Intell. Manuf. 2014, 28, 913-927. [CrossRef]

44. Hu, H.Y.; Chiu, S.I.; Yen, T.M.; Cheng, C.C. Assessment of supplier quality performance of computer manufacturing industry by using ANP and DEMATEL. TQM J. 2015, 27, 122-134. [CrossRef]

45. Krishankumar, R.; Ravichandran, K.S.; Saeid, A.B. A new extension to PROMETHEE under intuitionistic fuzzy environment for solving supplier selection problem with linguistic preferences. Appl. Soft Comput. 2017, 60, 564-576.

46. Kuo, T.C.; Wu, H.H.; Shieh, J.I. Integration of environmental considerations in quality function deployment by using fuzzy logic. Expert Syst. Appl. 2009, 36, 7148-7156. [CrossRef]

47. Kwong, C.K.; Chen, Y.; Bai, H.; Chan, D.S.K. A methodology of determining aggregated importance of engineering characteristics in QFD. Comput. Ind. Eng. 2007, 53, 667-679. [CrossRef]

48. Hsieh, K.L.; Tong, L.I.; Wang, M.C. The application of control chart for defects and defect clustering in IC manufacturing based on fuzzy theory. Expert Syst. Appl. 2007, 32, 765-776. [CrossRef]

49. Kaya, I.; Kahraman, C. Development of fuzzy process accuracy index for decision making problems. Inf. Sci. 2010, 180, 861-872. [CrossRef]

50. Yang, C.M.; Lin, K.P.; Chen, K.S. Confidence interval based fuzzy evaluation model for an integrated-circuit packaging molding process. Appl. Sci. 2019, 9, 2623. [CrossRef]

51. Ouyang, L.Y.; Hsu, C.H.; Yang, C.M. A new process capability analysis chart approach on the chip resistor quality management. Proc. Inst. Mech. Eng. Part B J. Eng. Manuf. 2013, 227, 1075-1082. [CrossRef]

52. Ouyang, L.Y.; Chen, K.S.; Yang, C.M.; Hsu, C.H. Using a QCAC-Entropy-TOPSIS approach to measure quality characteristics and rank improvement priorities for all substandard quality characteristics. Int. J. Prod. Res. 2014, 52, 3110-3124. [CrossRef]

53. Hsu, C.H.; Chen, K.S.; Yang, C.M. Construction of closed interval for process capability indices $C_{p u}, C_{p l}$, and $S_{p k}$ based on Boole's inequality and de Morgan's laws. J. Stat. Comput. Sim. 2016, 86, 3701-3714. [CrossRef]

54. Chen, K.S.; Hsu, C.H.; Ouyang, L.Y.; Yang, C.M. Applying MQCAC and fuzzy TOPSIS to improve the unleaded gasoline quality. J. Test. Eval. 2017, 45, 1045-1057. [CrossRef]

55. Chen, K.S.; Yang, C.M. Developing a performance index with a Poisson process and an exponential distribution for operations management and continuous improvement. J. Comput. Appl. Math. 2018, 343, 737-747. [CrossRef]

56. Kane, V.E. Process capability indices. J. Qual. Technol. 1986, 18, 41-52. [CrossRef] 
57. Chen, K.S.; Chen, H.T.; Tong, L.I. Performance assessment of processing and delivery times for very large scale integration using process capability indices. Int. J. Adv. Manuf. Tech. 2002, 20, 526-531. [CrossRef]

58. Chen, T.W.; Chen, K.S.; Lin, J.Y. Fuzzy evaluation of process capability for bigger-the-best type products. Int. J. Adv. Manuf. Tech. 2003, 21, 820-826. [CrossRef]

59. Yang, C.M.; Chen, K.S. Two-phase selection framework that considers production costs of suppliers and quality requirements of buyers. Int. J. Prod. Res. 2019, 57, 6351-6368. [CrossRef]

(c) (1)

(C) 2019 by the authors. Licensee MDPI, Basel, Switzerland. This article is an open access article distributed under the terms and conditions of the Creative Commons Attribution (CC BY) license (http://creativecommons.org/licenses/by/4.0/). 